\title{
A Qualitative Study on Factors that Influence Students' Food Choices
}

\begin{abstract}
Keywords: Adolescent; Qualitative; Nutrition; Food; Schools Abstract

Background: Few adolescents are eating recommended amounts of healthful food items at school. The purpose of this study was to gain an in-depth understanding of participating students' perception of their school menu, determine what influences their food choices, and solicit suggestions for improving the meals served in their schoo cafeteria.
\end{abstract}

Methods: Twelve focus groups among a total of 80 students were conducted among 7th to 12th grade students in school classrooms in the Lincoln Parish School District in Louisiana. Five focus groups were conducted with African-American students, five with White students, and two with both races combined. Students were asked about factors that influence their food choices and where they get nutrition knowledge. Responses were organized according to common themes and patterns and were guided by an ecological model.

Results: Multiple levels of influence on students' food choices were indicated, including taste, food appearance, the name of the food and/or familiarity with the food, cultural preferences, and perceived food safety. Students reported receiving little nutrition knowledge from school.

Conclusions: To promote healthy food choices in schools, schoo food service staff should consider offering taste testing sessions for new foods; improve food presentation by making food appealing; ensure food is cooked properly and monitor workers adherence to food safety standards, alleviate long lines during lunch periods and incorporate cultural practices such as seasoning or cooking methods. Nutrition education could be integrated into school curriculum and at the point-of-purchase to enhance these students' nutrition knowledge.

\section{Abbreviations}

NSLP: National School Lunch Program; USDA: United States Department of Agriculture; AA: African-American (AA)

\section{Introduction}

A typical person makes over 200 decisions about food each day [1]. For adolescents, this large number of food decisions has recently been overwhelmingly negative in terms of diet and health outcomes. Few adolescents are eating recommended amounts of whole grains, fruits and vegetables, and dairy products and are instead consuming high amounts of fast foods and high-sugar snack foods [2-4]. At the same time, obesity and diabetes in adolescents are increasing in prevalence and unhealthy dietary patterns have been considered one of the most frequent risk factors for chronic disease among adolescents [5]. Since students spend much of their time in a school and consume at least one meal there per day this setting provides an opportunity to influence what students eat [6].

Thus, understanding factors that influence an adolescent's food choices at school is important for designing future interventions to increase the consumption of healthy foods and beverages and

\section{Journal of}

Nutrition and Health

Mary W. Murimi ${ }^{1 *}$, Matthew Chrisman ${ }^{1}$, Heather R. McCollum $^{2}$ and Olevia Mcdonald ${ }^{2}$

${ }^{\prime}$ College of Human Sciences, Texas Tech University, Lubbock, Texas ${ }^{2}$ School of Human Ecology, Louisiana Tech University, Lubbock, Texas

\section{*Address for Correspondence}

Mary W. Murimi, College of Human Sciences, Department of Nutrition, Hospitality and Retailing, Texas Tech University, PO. Box 41240, Lubbock, TX 79409, USA, Tel: +1 (806) 843-1812; E-mail: mary.muimi@ttu.edu

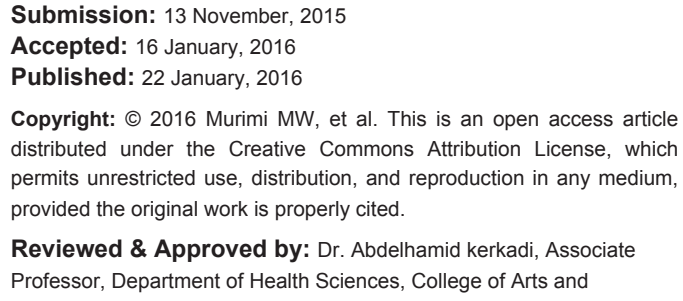

Reviewed \& Approved by: Dr. Abdelhamid kerkadi, Associate Professor, Department of Health Sciences, College of Arts and Sciences, Qatar University, Qatar

reduce consumption of unhealthy foods and beverages. An ecological approach provides a framework for understanding these factors at multiple levels of influence [7]. The United States Department of Agriculture (USDA) considers this multi-level framework crucial for understanding how all elements of one's environment shape their food and physical activity choices and subsequently, their health [8]. This type of approach includes consideration of policy issues, community and environment factors, and intrapersonal characteristics.

Policy issues that influence food choices include the Healthy, Hunger-Free Kids Act of 2010, which mandated that the USDA set guidelines for school wellness policies and nutrition education, as well as ensuring marketed foods and beverages, including breakfasts and lunches served at school, are consistent with health standards [9]. Meals in the National School Lunch Program (NSLP) are now required to offer only fat-free or 1 percent milk, limit total calories with less than 10 percent calories from saturated fat, reduce sodium, and minimize trans-fat [10]. During 2012 fiscal year approximately 31.6 million students participated in the NSLP daily, with more than 20 million of these receiving free or reduced price lunches [10].

Factors at the community and environment level can influence a child's eating behavior due to the availability of foods offered during school hours [11]. Children and adolescents spend a significant amount of time each weekday in the school environment; therefore, the school setting has the potential to be a practical and cost effective choice for interventions aimed at obesity prevention and reduction. Combined, school meals and snacks can provide up to $50 \%$ of a student's daily caloric intake [12].

Despite the importance of the previous factors, the most salient influence on adolescent eating patterns may be individual-level factors, especially as adolescents have more autonomy at school in regards to making food choices [13]. At the individual level, personal factors such as the physical senses and experience with a food are 
Citation: Murimi MW, Chrisman M, McCollum HR, Mcdonald O. A Qualitative Study on Factors that Influence Students' Food Choices. J Nutri Health. 2016;2(1): 6 .

ISSN: $2469-4185$

likely to influence an adolescent's food choices. Woo and Lee found that senses are important in children's food choices, especially taste and smell [14]. Similarly, the way food is named is important as indicated by a study by Wansink and colleagues, who found students were more likely to choose vegetables labeled with attractive names [15].

The factors that influence adolescents' food choices at school have not been previously thoroughly examined from their perspective, particularly using an ecological framework. Focus groups were therefore conducted in high schools and junior high schools in one school district in northern Louisiana, with the purposes of gaining an in-depth understanding of students' perception of the school menu, determine multi-level influences on their food choices, and solicit suggestions for improving the meals served in the school cafeteria.

\section{Methods}

\section{Participants}

During the 2011-12 school year, traditional focus groups were conducted among students from 6th to 12th grade in the Lincoln Parish School District, which was chosen because it provided a geographical diversity of urban and rural, and ethnicity. This school district, located in north-central Louisiana, serves almost 6,000 students in grades pre-kindergarten through 12 among 15 schools. Slightly over half (55\%) of the residents are Caucasian and $41 \%$ are of African-American (AA) descent, $40 \%$ of the county is rural, and almost 30\% have an income below poverty level [16]. Students were recruited from all five of the junior high and high schools in the district to capture students from the six grade levels, which encompass students ages 12-19. All students were given a letter describing the study procedures to take home for their parents to sign in order to be eligible for the study, and every student who returned with a signed parental consent form was allowed to participate.

In order to capture age- and culturally-related perceptions, focus groups were organized by grade levels and race where possible. A total of five focus groups were conducted with African American students, five with Caucasian students, and two focus groups with a mix of both races. At least two focus groups were conducted in each school, and the two biggest schools in the district had three focus groups. The focus group sessions were conducted during general classes that were representative of students from all grades, races and gender in each school. Students were excluded if they did not have a signed parental consent form or if they did not have a signed assent form. No incentives were provided for participating.

\section{Instrumentation and procedure}

The researchers formulated a semi-structured focus group topic guide and group segmentation guidelines and a list of questions that were asked can be found in Table 1 [17]. The questions were designed to gain a sense of factors that influence adolescent eating patterns, including the healthfulness of school menu items. The topic guide was not designed specifically based on an ecological model, but rather, questions were left open-ended to gather a broad array of multi-level influences.

Focus groups ranged from 8-12 members per group and lasted approximately 60 minutes. Two researchers experienced in focus group interviews moderated all the sessions, while two other research
Table 1: Focus group topic guide for high school students in the (blinded for review) school district.

- What influences your food choices? (in general, and in your cafeteria)

- Do you participate in your school meal program? Why or why not?

- When you think about eating healthy, what kind of foods do you think about? Which are available in your school cafeteria? What is missing that you wish were available?

- How often do you make these healthy choices when they are available in your school cafeteria?

- What foods do you consider less healthy in your school cafeteria? Why do you think they are less healthy?

- How often do you make less healthy choices when they are available in your school cafeteria?

- How would you judge the food temperature in your cafeteria?

- What school food changes in the past year do you like? What changes don't you like?

- Have your eating habits changed at school since last fall? In what ways have they changed?

- Do you feel like you have enough room to eat comfortably? Is the cafeteria bright enough during meals? Are the foods arranged conveniently? Is there anything that you would like to change about the physical layout or design of your cafeteria?

- What time do you go to lunch? What time would you prefer to take your lunch?

- Do you feel like you have enough time to finish your food during lunch? Do you feel like you spend too much time standing in the serving and checkout lines?

- How many times in a day do you use the vending machines? Where is the vending machine located? Does the location influence how often you use it?

-Where do you get your nutrition information from?

- What kinds of information do you need to make healthy food choices?

- Would the availability of information in the cafeteria influence your food choices?

- What can your school do to promote healthy eating?

team members observed and recorded the sessions in addition to writing supplemental field notes. Notes included comments on the conversation, the tone of voice, non-verbal observations and body language, and words used for description which were used in the analysis [17]. All focus group sessions were audio recorded and transcribed verbatim. Focus groups were chosen to give the students an opportunity to discuss their opinions, perspectives and desires in more detail than is typically allowed in traditional surveys.

\section{Data analysis}

Four researchers with experience in focus group interviews independently coded the transcripts, and one researcher with a background in the African American community provided assistance with cultural concepts and terminology. Each researcher examined a transcript of the quotations and comments from focus group participants and placed statements into common categories and issues. Data were then coded into broader themes. The researchers then met and discussed their findings, and discrepancies among themes and categories were deliberated. From this process, meaningful conclusions about the students' perspectives were drawn and any disagreements were discussed until full agreement was reached by all four researchers $[18,19]$. The conclusions were substantiated directly by supportive quotations from the students.

\section{Results}


Citation: Murimi MW, Chrisman M, McCollum HR, Mcdonald O. A Qualitative Study on Factors that Influence Students' Food Choices. J Nutri Health. $2016 ; 2(1): 6$

ISSN: $2469-4185$

A total of 80 students were interviewed across 12 focus groups. The majority were in grades 9-12 (high school; 62.5\%), female (67.5\%), and white (53.75\%). Table 2 presents brief demographic characteristics of the focus group participants, and Table 3 breaks down each focus group by school and participants' race. Analyses indicated that individual and environmental factors were most important for influencing school food choices according to the ecological framework and results are presented by the main individual and environmental themes that were revealed. In response to questions regarding factors that influence students' school food choices, the following themes were identified: Food sensory, which included the taste, smell and appearance of food; the name and familiarity of the food; cooking method; the length of the lunch line and food safety concerns. Regarding questions about nutrition knowledge and resources, students indicated they possessed inadequate knowledge of nutrition and that television and internet were their main sources of nutrition knowledge.

\section{Sensory aspect of the food: taste, appearance, and smell}

All of the focus groups, regardless of grade or race, indicated that taste was an important factor in deciding what food to choose, or more specifically, what to avoid. One student remarked that "the food they serve doesn't please my taste buds" (AA female, 11th grade). Underscoring the importance of taste, another student stated "I'll still eat it if it tastes good although I know it's not good for me" (AA male, junior high). Other comments were related to specific foods: one student mentioned that "wheat bread tastes nasty" (AA female, 10th grade) and another expressed a dislike for skim milk, noting that it

Table 2: Demographic characteristics of the (blinded for review) School District participants, 2011-12 school year.

\begin{tabular}{|l|c|c|}
\hline Variable & Category & $\mathbf{N}(\%)$ \\
\hline School type & High School & $50(62.5)$ \\
\hline \multirow{2}{*}{ Gender } & Junior high & $30(37.5)$ \\
\hline & Female & $54(67.5)$ \\
\hline Race & Male & $26(32.5)$ \\
\hline & African American & $37(46.25)$ \\
\hline
\end{tabular}

Table 3: Focus groups breakdown by school type, number of participants, and races represented in the (blinded for review) School District.

\begin{tabular}{|l|c|c|}
\hline School $^{\mathbf{a}}$ & Focus group(s) N $^{\text {N }}$ & Races represented $^{\mathbf{b}}$ \\
\hline Grambling HS & 10 & AA \\
\hline Ruston HS & 7 & AA \\
\hline Choudrant HS & 10 & Caucasian \\
\hline Simsboro HS & 10 & Caucasian \\
\hline & 7 & AA \\
\hline Grambling JHS & 6 & AA \\
\hline Ruston JHS & 9 & Mixed (6 Caucasian, 5 AA) \\
\hline Choudrant JHS & 11 & Caucasian \\
\hline
\end{tabular}

${ }^{\text {a }} \mathrm{HS}=$ high school; $\mathrm{JHS}=$ junior high school

${ }^{\mathrm{b}} \mathrm{AA}=$ African-American "tastes like water". When asked how they know if a food tastes good, they described either having eaten it before or if their friends tried it first.

In addition to how the food tasted, the appearance and smell of food was an important gatekeeper and was mentioned by all of the focus groups. General comments included that "If it looks and smells bad, I ain't eating it" (Caucasian female, 12th grade) and another student added that they "determines the food I eat by the smell and the look of it" (Caucasian male, 12th grade). Unappealing appearance or food presentation was again referred to as 'nasty': one student stated "If it looks nasty I probably won't eat it. I eat it because it looks good" (Caucasian female, 12th grade) and another student observed that "fish served in the school cafeteria smells nasty. I smell it even outside of a cafeteria and I do not eat [it]" (AA male, junior high). When asked how to improve the foods offered, one student made a recommendation to "make healthy foods look and taste good" (Caucasian male, 12th grade).

\section{Familiarity and the name of the food items}

Unfamiliar foods were less likely to be chosen. For example, one student stated "If we've tasted it before, we'll probably eat it. If we haven't tasted it before, then we probably won't eat it" (AA female, junior high). Specific examples of unfamiliar foods included brown rice and sweet potato fries. One barrier for choosing a food to eat was having unfamiliar name, which was particularly emphasized by the African-American focus groups. Students indicated they will not even consider dishes with unfamiliar names: "Sometimes if I don't know what it's called...I probably won't want to eat it" (AA male, 10th grade). Another student provided a specific example: "Potatoes Au Gratin-what is it?" (AA female, 11th grade). On the other hand, a familiar ingredient was a positive cue for choosing to eat a food; for example, one student mentioned: "I would eat new food if I saw something I like on it, such as a blueberry topping".

\section{Cooking method}

African American students indicated a preference for specific cooking methods, and even expressed frustration that some foods were baked versus fried. For example, one mentioned "they bake fries; baked fries are too soft and not crunchy" (AA female, 11th grade). Several other African American students also expressed a desire to see more fried foods. One student stated: "I would not be okay if catfish was steamed or boiled because I like it tasty. It is not tasty at all when it isn't greasy" (AA female, 12th grade). White students were more likely than the African American students to complain about lack of sweet choices: "They took away cinnamon rolls. Cinnamon rolls are huge and so sweet. I miss cinnamon rolls" (female, 11th grade). Another white student stated "I consider cake less healthy because they are sweet, but I want to have cake back" (male, 10th grade). Finally, all of the students, regardless of their race, preferred the use of spices to improve the taste of school food. One Caucasian male in 10th grade stated that "I know foods served in my school cafeteria are healthier since my school menu changed, but I do not like them. It was spicy previously, but now it's plain. It does not have flavor". This comment may reflect a common preference for seasoned and slightly spicy food in the southern US.

\section{Long lunch lines}


Citation: Murimi MW, Chrisman M, McCollum HR, Mcdonald O. A Qualitative Study on Factors that Influence Students' Food Choices. J Nutri Health. 2016;2(1): 6

In addition to the sensory and familiarity factors described above, waiting too long in line was identified as a barrier to participating in the school lunch program in all but two of the focus groups. Several students commented on long lunch lines, saying for example: "If the line is too long I walk away and get something unhealthy at the concession stand. I have a 30-min lunch break. I have waited in a line for 15 min. I do not have enough time to finish my lunch" (Caucasian male, 12th grade). Another student mentioned that "I got in line for what I wanted the other day and they had sixteen left and I was number seventeen. And the other lines [were too long] so I just left" (AA female, 11 th grade). Students were also frustrated at the organization of the cafeteria and food service staff and the time they take to serve as a result, stating that "when they run out of foods, they have to go in the back to get them. They should already have it right there" (AA male, 9th grade).

\section{Food safety}

There were several concerns related to food safety that were discussed in more than half of the focus groups, with the majority of complaints coming from the African-American groups. Students wondered about the cleanliness of the cafeteria and noticed cafeteria workers sometimes did not wear their gloves or hair nets. One student described a poignant observation regarding the cafeteria workers: "The other day there was this woman she was about to serve me and then her phone rang and she didn't even take off her gloves, she got her cell phone and she started talking on it and she hung up and started serving my food again without [removing and replacing] the gloves" (Caucasian female, junior high).

Several students mentioned finding human hair in their food, including one who stated "I had mashed potatoes once... and there was this big hair on it" (AA female, 10th grade), and others mentioned the food is not always cooked all the way through, noting that their "hamburger meat still be pink" (Caucasian female, 10th grade). Another student commented that the eating environment was not appropriate: "when we sit down at the tables, sometimes they still are dirty" (AA male, 9th grade), indicating a need for schools to ensure clean and healthy eating environments for their students.

\section{Inadequate nutrition knowledge}

The students were asked how much education in nutrition they had received and the source of that education. All students indicated that they had limited nutrition education, and denied learning nutrition in school, as exemplified by one students' statement: "I don't know about nutrition" (AA male, junior high). Rather, the students mentioned their nutrition information came from the internet and television.

The students were also asked what information they needed in order to make healthy food choices and their responses included: knowing what is actually in the food, the amount of calories, sugar, fat, and protein, and presence of allergens. When asked what foods were healthy, the students described fruits and vegetables, and mentioned grilled chicken salad as a healthy choice they would choose. They provided recommendations for the school to promote healthy eating, which included: "give us the food we like", "let us have a choice", "cook it better", "make it more appealing", "provide more desserts" and "serve foods at proper temperatures". When students were asked how often they make less healthy choices from their school cafeteria, common responses were 3-4 times per week or every day.

\section{Discussion}

This study revealed factors that influence students school food choices. When the students' responses were examined as products of an ecological framework, individual and environmental level factors were the most discussed in this study, which supports recent findings $[20,21]$. One of the main individual level factors influencing students' food choices was their use of their senses, including taste, smell and appearance. It was apparent that visual appearance and smell were gatekeepers for these students' food choices and these senses preceded their ability to taste a food. This is especially pertinent since students discussed they would only eat foods that looked and smelled good. These findings support several qualitative studies including: Stevenson and colleagues, who reported aesthetic qualities like taste, texture, appearance and smell were among the most powerful reinforces of food choices among adolescents, Nago and colleagues, who also found sensual properties like smell, color or shape were the most important factors adolescents discussed as influencing their food choices and Molaison and colleagues, who found African American adolescents preferred foods that tasted good, and in particular avoided foods that tasted "nasty" [22-24]. Although these findings are not groundbreaking they have policy and practice implications. Giving students the opportunity to define what tastes good, including incorporating spices in the cooking methods and engaging students in menu planning, would result in higher acceptance of food prepared in school and could increase participation in school meal programs.

Familiarity with a food was also important to these students' food choices, representing another individual level influence. The students were more likely to choose a food they or their friends had tried before. On the other hand, being unfamiliar with a food, including not recognizing the name of a food, was presented as a barrier to choosing that food. Students stated they would not eat a food if they did not know what it was. Therefore, opportunities to try a food may be an important step for encouraging these students to choose new foods. The HEALTHY study group conducted an intervention in schools that incorporated taste tests of new and unfamiliar foods as one intervention component, and found intervention schools served less energy ( 38 calories, $\mathrm{P}=0.02$ ), total fat ( 2.7 grams, $\mathrm{P}=0.001$ ), percent energy from fat $(4.5 \%, \mathrm{P}<0.001)$, and more fiber in grainbased foods and legumes $(0.8$ grams, $\mathrm{P}<0.001)$ than control schools [25]. Taste tests might be an effective strategy for engaging students in menu planning and familiarizing students to new foods, which might result in increased acceptance of school food.

Extending beyond individual level factors, broader cultural factors that influenced students' food choices included preferences for certain cooking methods (like frying foods) and the use of seasoning. Similarly, Campbell reported that low-income, minority adolescents preferred fried foods to other cooking methods, and a study of African American adolescents by Wang and colleagues found that fried food consumption was high, which may be indicative of cultural dietary patterns in the general African-American population $[26,27]$. Therefore, it is important to consider cultural factors when developing and introducing new food choices for adolescents and these factors should also be incorporated into any nutrition education 
Citation: Murimi MW, Chrisman M, McCollum HR, Mcdonald O. A Qualitative Study on Factors that Influence Students' Food Choices. J Nutri Health. 2016;2(1): 6 .

provided to them [28].

Environmental factors also created challenges for what foods the students chose. For example, long lines in the cafeteria influenced whether students had enough time to eat their food, or if the food they wanted was available. When the food they wanted ran out or the lunch lines were too long, the students indicated that they sometimes bought "unhealthy" food from concession stands. These environmental factors should be considered by schools attempting to promote healthier items, especially considering that students may have more autonomy in food choices while at school versus at home [13]. Similarly, it is crucial that the food service does not put the students in a position between being tardy in a class and missing a healthy meal. Making sure the lunch delivery system is effective given the short lunch periods (such as adding more lines to reduce the time it takes to receive a meal) would encourage more participation.

The students' assessment of food safety was unique and greater than expected, and indicated an additional environmental factor that affected their food choices. They perceived food safety being related to the physical appearance of the cafeteria workers, such as wearing hair nets and gloves, and through food being cooked properly. Students desired their food to be cooked all the way through and served warm or hot when appropriate, and were concerned when cafeteria workers did not abide by food safety guidelines. Although these findings may be somewhat self-evident, they can influence school health by encouraging stricter adherence to food safety guidelines and ensure proper training is received for all food service staff.

The students' self-reported nutrition knowledge was low as several students mentioned that no one gave them information about nutrition, even at school. This is supported by the findings of a previous study of multi-ethnic high school students, who reported minimal knowledge of food and nutrition [26]. The students were aware of some healthy and unhealthy food items, but they openly acknowledged a lack of knowledge regarding nutrition or nutrient composition such as number of calories in a given food. Although knowledge alone does not always enable adolescents to adopt healthy eating behaviors, it may be a prerequisite for behavioral interventions [28]. While nutrition knowledge was not objectively assessed in this study, it was clear that the information the students requested related to the energy density of a meal such as the amount of calories or fat in a meal. It is possible to provide that information through the cafeteria where food choices are made. Nutrition education could be integrated into classroom activities, such as combining nutrition and mathematics, teaching food labels based on the school menu, or being discussed in gym classes; ideally, a coordinated school health program (such as a required health class) could be developed to disseminate nutrition information. Also, because sensory experiences were important to these students, this could be integrated into classroom activities, such as presenting actual fruit and vegetables when discussing biology or chemistry.

Research for changing school menus to address students' food preferences should involve several key multi-level influences that were revealed by this study: samples of all food changes should be offered allowing students an opportunity to try them; the appearance of food should be addressed by making it appealing; food should be cooked properly and all workers adhere to food safety standards that are actively enforced; long lines should be alleviated during meal periods; and cultural practices such as seasoning or cooking methods should be considered when developing new food items. An ecological framework provides a useful model for targeting such influences.

\section{Limitations}

This study was limited to one school district, and findings may not be generalizable to other schools or geographic regions in the country. Students were only included if they had a signed parental consent form, and those students may not be representative of the entire student population. It is not known if there are any differences between participants and non-participants. Participants were encouraged disclosing any opinions on the discussion topics, but statements made may have been socially desirable or inaccurate. Actual food purchases were not assessed in this study, and it is not known how accurately the opinions expressed by the students reflect their consumption of the foods they discussed. However, underlying findings can be applied to increase school food participation elsewhere.

\section{Conclusions}

The student focus group discussions in this study provide rich descriptive data regarding multi-level factors influencing adolescent food choices, and may help in increasing the acceptance rate of the school food. Findings from this study underscore the importance of engaging students in menu preparation and selection. Students demonstrated a priority for aesthetics of their food presentation over that of healthy choices, revealing a challenge for food service directors to present school food in an attractive manner and to ensure the food tastes good. If students are going to taste the food, the food's appearance should be an important factor to all food service staff wanting to increase participation in the school meal programs. Use of taste testing sessions to expose students to new menu items would be an effective strategy successfully used in marketing to increase food acceptability. Taste, visual appeal, and cultural/ethnic appropriateness are factors that should be considered when designing school menus to ensure that students will support the foods offered, and Wansink, et al. also suggest using familiar and attractive words when naming foods in order to enhance the opportunity of that food being chosen $[29,15]$.

Additionally, federally funded school lunch programs are required to design a wellness plan providing nutrition education, and the findings from this study indicate that such a program was not identified as a source of nutrition knowledge by the students which could be targeted in nutrition education efforts [30]. Results from this study will be used to inform the development of high school menu changes in this population.

\section{References}

1. Wansink B, Sobal J (2007) Mindless eating: The 200 daily food decisions we overlook. Environ Behav 39: 106-123.

2. Rasmussen M, Krolner R, Klepp KI, Lytle L, Brug J, et al. (2006) Determinants of fruit and vegetable consumption among children and adolescents: a review of the literature. Part I: quantitative studies. Int J Behav Nutr Phys Act 3: 22.

3. Krebs-Smith SM, Guenther PM, Subar AF, Kirkpatrick SI, Dodd KW (2010) Americans do not meet federal dietary recommendations. J Nutr 140: 18321838. 
Citation: Murimi MW, Chrisman M, McCollum HR, Mcdonald O. A Qualitative Study on Factors that Influence Students' Food Choices. J Nutri Health. 2016;2(1): 6 .

4. Niemeier HM, Raynor HA, Lloyd-Richardson EE, Rogers ML, Wing RR (2006) Fast food consumption and breakfast skipping: predictors of weight gain from adolescence to adulthood in a nationally representative sample. $J$ Adolesc Health 39: 842-849.

5. Lowry R, Kann L, Collins JL, Kolbe LJ (1996) The effect of socioeconomic status on chronic disease risk behaviors among US adolescents. JAMA 276 792-797.

6. Story M, Nanney MS, Schwartz MB (2009) Schools and obesity prevention: Creating school environments and policies to promote healthy eating and physical activity. Milbank Q 87: 71-100.

7. Sallis JF, Owen N, Fisher EB (2008) Ecological models of health behavior In: K. Glanz, BK Rimer, K Viswanath (Eds.), Health behavior and health education: Theory, research and practice. $4^{\text {th }}$ ed. San Francisco: JosseyBass pp.465-485.

8. United States Department of Agriculture (2010) Dietary guidelines for Americans.

9. (2010) S.3307--111th Congress: Healthy, hunger-free kids Act of 2010.

10. FRAC (2012) Healthier school meals: A summary of the new USDA standards for school breakfast and lunch. Food Research and Action Center.

11. Bevans KB, Sanchez B, Teneralli R, Forrest CB (2011) Children's eating behavior: The importance of nutrition standards for foods in schools. J Sch Health 81: 424-429.

12. Larson N, Story M (2009) A review of environmental influences on food choices. Ann Behav Med 38 Suppl 1: S56-S73.

13. Fitzgerald A, Heary C, Nixon E, Kelly C (2010) Factors influencing the food choices of Irish children and adolescents: a qualitative investigation. Health Promot Int 25: 289-298.

14. Woo T, Lee KH (2013) Effects of sensory education based on classroom activities for lower grade school children. Nutr Res Pract 7: 336-341.

15. Wansink B, Just DR, Payne CR, Klinger MZ (2012) Attractive names sustain increased vegetable intake in schools. Prev Med 55: 330-332.

16. US Census Bureau (2014) State \& county QuickFacts: Lincoln Parish, Louisiana. US Dep Commer Econ Stat Adm.
17. Krueger RA (2009) Focus groups: a practical guide for applied research (4thedn). Thousand Oaks, CA: Sage Publications.

18. Mayring P (2000) Qualitative content analysis. Forum Qualitative Sozial forschung/ Forum. Qualitative Social Res.

19. Patton MQ (1987) How to Use Qualitative Methods in Evaluation (2ndedn), Newbury Park, CA: Sage Publications.

20. Verstraeten R, Van Royen K, Ochoa-Aviles A, Penafiel D, Holdsworth M, et al. (2014) A conceptual framework for healthy eating behavior in Ecuadorain adolescents: A qualitative study. PLOS One.

21. Deliens T, Clarys P, De Bourdeaudhuij I, Deforche B (2014) Determinants of eating behavior in university students: a qualitative study using focus group discussions. BMC Public Health 14: 53.

22. Stevenson C, Doherty G, Barnett J, Muldoon OT, Trew K (2007) Adolescents' view of food and eating: identifying barriers to healthy eating. J Adolesc 30 : 417-434.

23. Nago ES, Verstraeten R, Lachat CK, Dossa RA, Kolsteren PW (2012) Food safety is a key determinant of fruit and vegetable consumption in urban Beninese adolescents. J Nutr Educ Behav 44: 548-555.

24. Molaison EF, Connell CL, Stuff JE, Yadrinck MK, Bogle M (2005) Influences on fruit and vegetable consumption by low-income black american adolescents. J Nutr Educ Behav 37: 246-251.

25. HEALTHY Study Group, Mobley CC, Stadler DD, Staten MA, El Ghormli L, et al. (2012) Effect of nutrition changes on foods selected by students in a middle school-based diabetes prevention intervention program: the HEALTHY experience. J Sch Health 82: 82-90.

26. Campbell E (2009) Dietary choices of urban minority high school students Pediatr Nurs 35: 171-180.

27. Wang Y, Jahns L, Tussing-Hymphreys L, Xie B, Rockett H, et al. (2010) Dietary intake patterns of low-income urban african-american adolescents. J Am Diet Assoc 110: 1340-1345.

28. Contento IR, Manning AD, Shannon B (1992) Research perspective on school-aged nutrition education. J Nutr Educ Behav 24: 247-260.

29. Byker CJ, Pinard CA, Yaroch AL, Serrano EL (2013) New NSLP guidelines: Challenges and opportunities for nutrition education practitioners and researchers. J Nutr Educ Behav 45: 683-689.

30. (2004) Text of the child nutrition and WIC Reauthorization Act of 2004 Congress.

\section{Acknowledgements}

This research was supported by a planning grant agreement Number 59-5000-0-0071 from the USDA's Food Assistance and Nutrition Research Programs, USDA: ERS. The Authors would like to thank the Food service director and staff of Lincoln Parish School District for their support in data collection. 